\section{Physiological Responses of Turfgrass Species to Drought Stress under High Desert Conditions}

\author{
Nisa Leksungnoen', Paul G. Johnson, and Roger K. Kjelgren \\ Department of Plants, Soils, and Climate, Utah State University, 4820 Old \\ Main Hill, Logan, UT 84322-4820
}

Additional index words. kentucky bluegrass, tall fescue, drought stress, Intermountain West climate, stomatal conductance, leaf water potential, volumetric water content

\begin{abstract}
Broad concerns over water shortages and drought where irrigated urban landscapes are common in high desert regions have focused attention on drought tolerance of turfgrass species. We investigated the physiological responses of kentucky bluegrass (KBG) and tall fescue (TF) under a prolonged drought under high desert conditions. The experimental design was a split plot with three replicates. Two irrigation treatments as a whole plot-well-watered and no water-were applied to subplots of 'Midnight' KBG and 'Gazelle' TF. Stomatal conductance $\left(g_{\mathrm{S}}\right)$, canopy temperature, and predawn leaf water potential were measured over two seasons. KBG $g_{S}$ and leaf water potential decreased faster and to a greater extent than $\mathrm{TF}$ in response to soil drying, and KBG was in complete dormancy and brown within 5 weeks after cessation of irrigation. By contrast, TF maintained a green canopy throughout the drought periods. In the nowater plots, TF appeared to consume water from the deepest measured soil profiles $(80$ to $100-\mathrm{cm}$ depth), whereas KBG used most of the water in the 50- to $60-\mathrm{cm}$ depths. When watered for recovery in late summer, KBG plots were mostly green within 3 weeks after rewatering. The surface temperature of the well-watered plots was $6-13{ }^{\circ} \mathrm{C}$ cooler than the no-water plots and TF showed $5-7^{\circ} \mathrm{C}$ lower temperature than $\mathrm{KBG}$ in no-water plots. TF is suitable for deep soil, exploiting a larger volume of water to avoid drought, whereas KBG's rapid drought avoidance would likely perform better in shallow landscape soils under drought.
\end{abstract}

The Intermountain West (IMW) of North America is considered a high desert environment and is experiencing substantial population growth that means increasing demand for water, particularly as a result of irrigated urban landscapes (Kjelgren et al., 2000). Hot, dry summers are characteristic of the IMW, where urban turfgrass requires irrigation to survive and thereby driving demand for water. However, the IMW has very limited water supplies; thus, water conservation in irrigated urban landscapes has become an important policy to moderate consumption (Hilaire et al., 2008). Hydrological drought resulting from low winter snowpack is very common in the IMW and often leads to water conservation measures that can result in water stress of landscape plants, particularly turfgrass. Additionally, high temperatures and low humidity can increase drought stress on plants when irrigation is insufficient.

Drought tolerance refers to the ability to experience and undergo drought stress but survive (Fry and Huang, 2004). Plants adapted

Received for publication 24 May 2011. Accepted for publication 7 Nov. 2011.

We thank the Ananthamahidol Foundation, the Utah Agricultural Experiment Station, and the Center for Water Efficient Landscaping for supporting this experiment.

${ }^{1}$ To whom reprint requests should be addressed; e-mail nisa.leksungnoen@aggiemail.usu.edu. to water-limiting environments such as the IMW use a variety of adaptive mechanisms (McCann and Huang, 2007). Stomata control the exchange of water vapor and $\mathrm{CO}_{2}$ between the interior of the leaf and the atmosphere, which contributes to control of the plant's internal water status and to gaining carbon for photosynthesis (Hetherington and Woodward, 2003). Plants prevent water loss by closing stomata to reduce transpiration, but at the cost of reducing evaporative cooling, increasing leaf temperature, and decreasing photosynthesis and growth (Fry and Huang, 2004).

Stomatal closure with increased vapor pressure deficit of ambient air (VPD) is common in many plants to moderate transpiration under high evaporative demand (Bates and Hall, 1981; Monteith, 1995; Turner et al., 1984). More specifically, stomatal sensitivity is driven by leaf-to-air vapor pressure difference (LAVPD) for species in dense canopies (like turf) or with large leaves with boundary layers that limit convective heat loss (Landsberg and Butler, 1980; Montague et al., 2000; Turner, 1991). For such species, drought can trigger a feed-forward loop of progressively increasing LAVPD and stomatal closure until transpirational evaporative cooling is balanced by convective cooling (Jones, 1999). Progressive drought stress hastens this loop and increases stomatal sensitivity to LAVPD and correlates with decreased evapotranspiration rates (Al-Faraj et al., 2001).
Turfgrass species used in the IMW avoid drought but differ in mechanisms. TF avoids drought because it maintains normal physiological function in water-limiting conditions by developing an extensive, deep root system to extract more water from a deeper and greater volume of soil (Huang and Gao, 2001). This postpones tissue dehydration (Sheffer et al., 1987). TF appears to also reduce water loss from transpiring leaves by rolling its leaves as soil water content declines (Qian and Fry, 1997). By contrast, KBG avoids drought by entering summer dormancy (Ervin and Koski, 1998), sometimes referred to as quiescence. However, once adequate moisture is again available, plants will resume active growth (Laude, 1953).

Osmotic adjustment is another drought tolerance mechanism that grasses use to maintain cellular turgor and allow them to take up water at lower soil water potentials (Perdomo et al., 1996; White et al., 1992). Osmotic adjustment under stress conditions has been reported to occur in both TF (Qian and Fry, 1997; West et al., 1990; White et al., 1992) and KBG (Jiang and Huang, 2001; Perdomo et al., 1996).

Grass responses during prolonged summer drought have long been studied. Most research has been conducted in greenhouses under controlled conditions (Aronson et al., 1987; Brown et al., 2004; Qian and Fry, 1997), whereas some were field investigations (Carrow, 1996; Laude, 1953; Richardson et al., 2008). Traits used to measure drought response have more commonly included morphological responses such as growth reduction, turfgrass quality rating, and root density (Ervin and Koski, 1998; Qian and Fry, 1997; Sheffer et al., 1987). Less often but more recently, physiological responses such as water relations, $g_{\mathrm{S}}$, photosynthesis, and hormone (abscisic acid) concentration have been measured (Jiang and Huang, 2000; Perdomo et al., 1996; Volaire et al., 2009; West et al., 1990).

Because the mechanisms that KBG and TF use to cope with drought are quite different, a comparison under common field conditions, with detailed measurements, will help us understand the distinct drought tolerance or avoidance mechanisms used by these grasses. The objective of this work was to compare the physiological responses of KBG and TF, which differ in drought-coping mechanisms, that might contribute to persistence of field-grown grasses during a prolonged drought in the IMW.

\section{Materials and Methods}

Field plot. 'Midnight' KBG (Poa pratensis L.) and 'Gazelle' tall fescue [Schedonorus phoenix (Scop.) Holub] were planted at the Greenville Research farm in North Logan, UT (lat. $41^{\circ} 45^{\prime} \mathrm{N}$, long. $111^{\circ} 48^{\prime} \mathrm{W}$ ) in 2003. Temperature and precipitation data at the experimental site are summarized in Figure 1. The soil at the experimental site was a silt loam, Millville series of uniform depth with a pH of 7.8-8.2 (Abdu et al., 2007). The experimental design was a split 


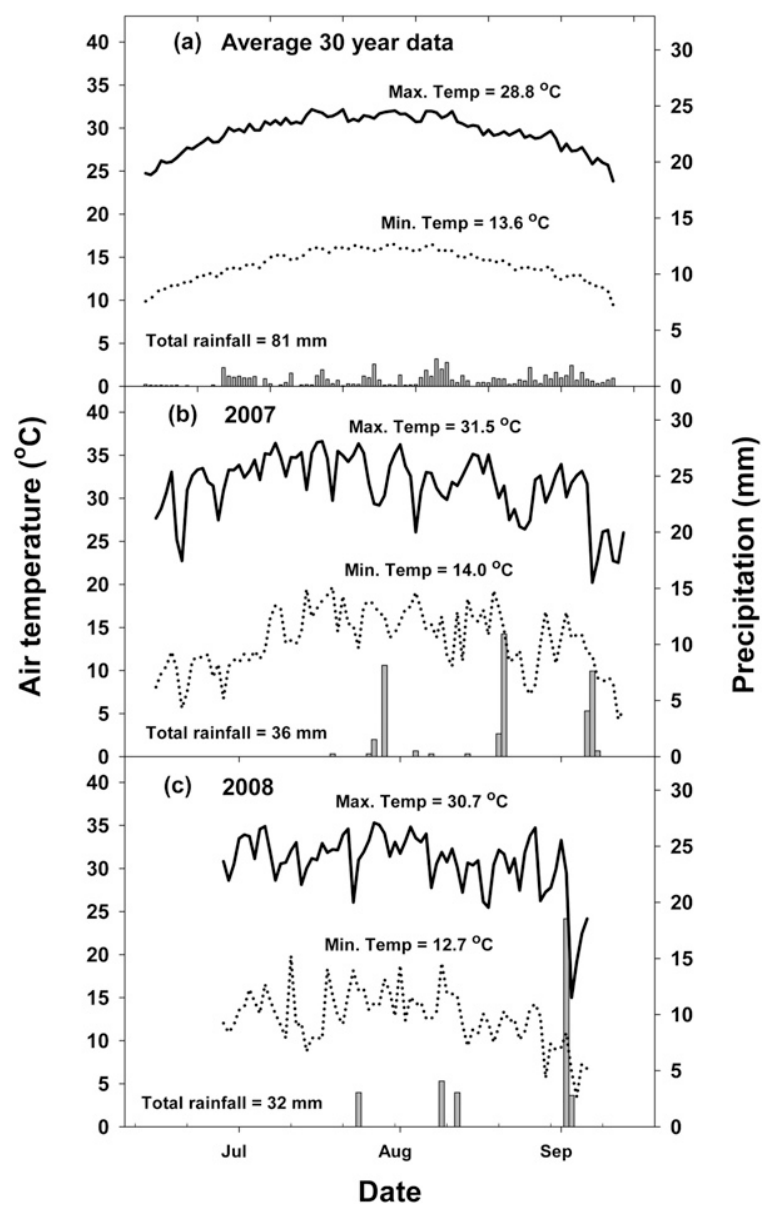

Fig. 1. Daily maximum and minimum air temperature and precipitation in (A) a 30-year period (B) 2007 and (C) 2008 .

plot with six main plots of $3 \times 6 \mathrm{~m}$ each divided into six subplots, each $1.5 \times 2 \mathrm{~m}$. Subplots were randomly assigned within each main plot and planted with a different turfgrass species.

Two irrigation treatments were applied to the whole plot area: 1) well-watered, irrigated three times a week with $1.2 \mathrm{~cm}$ of water; and 2) no-water plots that did not receive irrigation after 12 June in 2007 and 25 June in 2008. Well-watered plots were irrigated by hand to ensure uniformity and grasses were mowed at $7.62 \mathrm{~cm}$ and fertilized with ammonium sulfate at rate of $9.8 \mathrm{~kg} \cdot \mathrm{ha}^{-1}$, which was applied per year to the plots - half in the spring and half in the fall.

Plots were 4 years old and well established when measurements were begun. In 2007, measurements were made twice each week from 13 June to 22 Aug. and then irrigation was resumed for 3 weeks to recover from prolonged drought. In 2008, measurements were conducted once a week from 26 June to 7 Aug. and then irrigated to allow recovery for 4 weeks.

Measurements. Predawn leaf water potential measurements were made twice a week in 2007 and once a week in 2008 using a pressure chamber (Model 3005HGPL; Soil, Moisture Equipment Corp, Santa Barbara, CA). At predawn, five stems of each species in each subplot were collected by pulling the entire plant including the root, then immediately wrapping them in plastic wrap and storing in a bag filled with ice for transport to the laboratory. Stems were cut slightly above the root and placed in the pressure chamber. Nitrogen gas was slowly applied to increase the chamber's atmospheric pressure until water appeared at the cut end of the stem. The pressure reading was then taken and used as leaf water potential.

Stomatal conductance measurements were made twice a week in 2007 and once a week in 2008 using a leaf porometer (Model SC-1; Decagon Devices, Inc., Pullman, WA). Measurements were taken between $1100 \mathrm{HR}$ and 1400 HR on a clear day. Four to five blades of grass in each subplot were excised and arranged before clamping side by side with the adaxial side of the leaves facing the porometer chamber. Time used to prepare leaves for measuring after excising the leaves was less than $5 \mathrm{~s}$ to prevent the effect of water discontinuity on stomata. Stomata closure in lucerne occurred within $2 \mathrm{~h}$ after cutting for hay and when the relative water content in tall fescue leaves remained between $80 \%$ and $90 \%$, the $g_{\mathrm{S}}$ would not be affected by cutting (Harris and Tullberg, 1980). By using the instrument's automatic mode, the $g_{\mathrm{S}}$ was measured in $30 \mathrm{~s}$. Eight separate measurements were made from each subplot and averaged for a final value.
Surface temperature of each subplot was measured using a digital thermometer (Model 52-II Dual Input Digital Thermometer; Fluke Corporation, Everett, WA) connected with infrared (IR) temperature sensors (Model SI-111; Apogee Instruments, Inc., Logan, UT) after measuring $g_{\mathrm{S}}$ at $1400 \mathrm{HR}$ MDT. The IR temperature sensor was held $1 \mathrm{~m}$ above the canopy perpendicular to the ground allowing a field of view of $2 \mathrm{~m}$ in diameter.

Ambient air temperature data were continuously collected by a weather station in Greenville Research farm with a combination temperature and humidity sensor (Model CR500; Campbell Scientific, Logan, UT). The sensor was scanned every $10 \mathrm{~s}$ and averages were recorded every $30 \mathrm{~min}$ with a data logger (Model CR1000; Campbell Scientific). VPD and LAVPD were calculated using ambient air temperature, dewpoint temperature, and leaf temperature as described by Murray (1967).

VPD is the difference between saturation vapor pressure and actual vapor pressure of ambient air $\left(e_{s}-e\right)$, whereas LAVPD was calculated from the difference between saturation vapor pressure of the leaf using leaf temperature and actual vapor pressure of the ambient air $\left(e_{l}-e\right)$.

Volumetric soil water content (VWC) was measured in 2008 using a frequency domain reflectometry (FDR) sensor (Diviner 2000; Sentek Sensor Technologies, Adelaide, Australia). One-meter long polyvinyl chloride tubes were installed in the center of each subplot. Every day at 1600 HR, the Diviner 2000 probe was inserted into each access tube to measure water content to a depth of $100 \mathrm{~cm}$ (the deepest measurement of this study) with measurements made at $10-\mathrm{cm}$ intervals.

Percent water use in each depth $(10-\mathrm{cm}$ interval) was calculated by the following equation:

$$
\begin{aligned}
& \% \text { water use each depth }(10 \mathrm{~cm}) \\
& =\frac{V W C_{\text {initial }}-V W C_{\text {end }}}{\sum V W C_{\text {initial }}-V W C_{\text {end }}} \times 100 \%
\end{aligned}
$$

where $\mathrm{VWC}_{\text {initial }}$ is the volumetric soil water content at the beginning of the experiment and $\mathrm{VWC}_{\text {end }}$ is the volumetric soil water content at the end of the experiment.

Statistical analysis. The experiment was a split plot design with six whole plots with two treatments applied (well-watered and nowater treatments) and three replicates of each. Treatment effects, species differences, and treatments $\times$ species interactions were determined by analysis of variance according to the mixed procedure of SAS (Version 9.0; SAS Institute, Cary, NC). Thus, fixed parameters were species $\times$ treatments, whereas random parameters were replicates, replicates $x$ treatments, and replicates $\times$ species $\times$ treatment. Mean differences were tested with least significant difference test at a probability level of 0.05 . Slope comparison was tested using the GLM procedure of SAS. 


\section{Results}

The drought responses of the grasses varied slightly as a result of the difference in weather conditions between 2007 and 2008 (Fig. 1). Average air temperature in 2007 was $\approx 1$ to $2{ }^{\circ} \mathrm{C}$ higher than in 2008 ; however, average air temperature of both years was 2 to $3{ }^{\circ} \mathrm{C}$ higher than the 30 -year average. Moreover, total rainfall during both years was significantly lower than the 30 -year average (Fig. 1). It should be noted that during the study period, there were several rainfall events with minimal effect. Recently, there was a study in the same field, which indicated that it took greater than $13 \mathrm{~mm}$ of precipitation to restore active growth in turfgrass (unpublished data).

Because irrigation was withheld in the nowater plots, KBG entered summer dormancy in 5 weeks and all aboveground tissues were brown, whereas TF remained green with some browning for the whole period of each experiment in both years. Each year, $g_{\mathrm{S}}$ of KBG in well-watered and no-water plots was equal at the beginning of the experiment but in the no-water plots, conductance decreased rapidly after irrigation stopped (Fig. 2). Stomatal conductance differed from well-watered plots by Week 1 in both years. Unlike KBG, $g_{\mathrm{S}}$ of TF in no-water plots was significantly lower than in well-watered plots by Week 2 in both years. Irrigation was resumed on the no-water plots in August to end dormancy and restore active growth. The spike in Figure $2 \mathrm{E}$ at Day 48 was caused by $\approx 8 \mathrm{~mm}$ of rainfall (Fig. 1B) stimulating a rapid increase in $g_{\mathrm{S}}$ in no-water TF but not in nowater KBG.

After resumption of irrigation, $g_{\mathrm{S}}$ of nowater KBG equalized with that of wellwatered plots after 3 weeks in 2007 and 4 weeks in 2008. TF recovered to the same degree of $g_{\mathrm{S}}$ after 2 weeks in 2007 and after 4 weeks in 2008. Overall, $g_{\mathrm{S}}$ of KBG dropped lower and faster than that of TF in both years. However, it took about the same length of time for $\mathrm{KBG}$ and $\mathrm{TF}$ to recover from prolonged drought.

Predawn leaf water potential ( $\left.\psi_{\text {leaf }}\right)$ followed a similar trend to $g_{\mathrm{S}}$. As soil became drier, $\psi_{\text {leaf }}$ of KBG was more negative and significantly lower than well-watered $\psi_{\text {leaf }}$ by Week 2 in both years. KBG entered complete summer dormancy when $\psi_{\text {leaf }}$ dropped to $-2.0 \mathrm{MPa}$. In contrast, the $\psi_{\text {leaf }}$ of TF in nowater plots was significantly different from those in well-watered plots by Week 3 in 2007 and by the first week in 2008. The sharp decrease of $\psi_{\text {leaf }}$ in Day 43 in 2008 (Figs. 2D and $2 \mathrm{H}$ ) was the result of the difficulty of measurements the week before (Day 36) resulting in no data on that day, the initial week for KBG entering dormancy in 2007 and a rapid decline in internal water potential (Fig. 2B). During the recovery period, $\psi_{\text {leaf }}$ of both species increased (less negative) to well-watered plot levels after 2 weeks of recovery in 2007 and 3 weeks in 2008.

Surface temperature at midday of no-water vs. the well-watered plots was $\approx 6$ to $13{ }^{\circ} \mathrm{C}$ higher in both species, typical of droughtstressed turf, and manifested in a higher leaf and air temperature $\left(\mathrm{T}_{\text {leaf }} \mathrm{T}_{\text {air }}\right)$ difference in no-water than in well-watered plots $(P=$ 0.0008) (Fig. 3A). $\mathrm{T}_{\text {leaf }}-\mathrm{T}_{\text {air }}$ in well-watered plots declined similarly in both species as VPD increased as a result of evaporative cooling. This well-established inverse baseline relationship between $\mathrm{T}_{\text {leaf }}-\mathrm{T}_{\text {air }}$ and VPD for dense, uniform crop surfaces (Idso, 1982) has been conceptually refined (Blonquist et al., 2009) and applied to cool-season turfgrass (Martin et al., 2005). In the no-water plots, drought-induced stomatal closure (Fig. 2A-B) reduced evaporative cooling in both species. However, $K B G T_{\text {leaf }}-\mathrm{T}_{\text {air }}$ was higher than that of TF across all VPD levels as KBG entered dormancy and lost stomatal function.

In the well-watered plots, $g_{\mathrm{S}}$ decreased as the LAVPD increased with no difference in slope $(P=0.204)$ of both species (Fig. 3B). As drought stress became more severe, LAVPD was greater as a result of stomatal closure, leading to an increase in leaf temperature, in turn causing greater differences in LAVPD (Fig. 3C). However, in no-water plots, the reduction in $g_{\mathrm{S}}$ as LAVPD increased, indicated by the slope in Figure 3C, was also not significantly different $(P=$ 0.313 ) in both species at LAVPD less than 5 $\mathrm{kPa}$. At LAVPD above $5 \mathrm{kPa}$, TF stabilized $g_{\mathrm{S}}$ at $\approx 150 \mathrm{mmol} \cdot \mathrm{m}^{-2} \cdot \mathrm{s}^{-1}$, whereas $g_{\mathrm{S}}$ in $\mathrm{KBG}$ dropped to lower levels and continued to decrease over a progressively higher range of LAVPD levels than TF until complete $g_{\mathrm{S}}$ closure.

The rapid and progressive stomatal closure in $\mathrm{KBG}$ in response to soil drying is delineated more sharply when related to water potential (Fig. 4). The ratio of wellwatered to no-water of leaf water potential vs. $g_{\mathrm{S}}$ of both species showed a similar trend, decreasing as drought-induced $g_{\mathrm{S}}$ declined. This figure is similar to that of Kjelgren et al. (2009) but with the well-watered vs. no-water ratio inverted. Stomatal conductance of TF in no-water plants declined along with declining leaf water potential but no-water $g_{\mathrm{S}}$ did not fall below $30 \%$ of well-watered plants (ratio of well-watered to no water was not more than 3 ) while maintaining $\psi_{\text {leaf }}$ above $50 \%$ of well-watered plants. This trend was initially apparent in KBG as well, up to a well-watered to no-watered $g_{S}$ ratio of 2 ( $50 \%$ of well-watered plants), but over the space of a week, the ratio increased to 4 as no-water fell to $25 \%$ of well-watered $g_{\mathrm{s}}$. The ratio ultimately progressed to $10 \%$ (ratio of well-watered to no water was $\approx 10$ ) of wellwatered plants, whereas $\psi_{\text {leaf }}$ only fell to $50 \%$ to $40 \%$ of well-watered plants, in contrast to TF, which maintained an apparent steady-state balance between $g_{\mathrm{S}}$ and $\psi_{\text {leaf }}$. KBG went dormant after stomata completely closed and leaf water potential stopped decreasing (more negative), whereas TF maintained open stomata, allowing a somewhat green canopy during the dry-down period.

The greatest water use of plants in nowater plots was indicated by the greatest de- pletion to the lowest percent volumetric soil water content over the course of the study period (Figs. 5 and 6). KBG used more water from the soil at depths between 0 and $90 \mathrm{~cm}$, whereas TF used water down to $100 \mathrm{~cm}$ (greatest depth measured in this study) (Fig. 6); the large depletion at $100 \mathrm{~cm}$ suggested that TF likely extracted water below the measured root zone. Both species extracted more water at the surface $(0$ to $30 \mathrm{~cm})$ than at the deeper soil profile, but TF depleted more water at the deepest depths than KBG. In addition, the total amount of water used by TF was $9 \%$ higher than by KBG. To better evaluate which depths contributed the most to variation in $g_{\mathrm{S}}$, stepwise regression was used to relate soil depth as independent variables (Xs) and $g_{\mathrm{S}}$ as the dependent variable (Y). In well-watered plots, the shallow depths $(0$ to $20 \mathrm{~cm})$ contributed most to $g_{\mathrm{S}}$ in TF $(F=$ 0.033 and $\left.R^{2}=0.411\right)$ and at $60-$ to $80-\mathrm{cm}$ depths in $\operatorname{KBG}\left(F=0.014\right.$ and $\left.R^{2}=0.509\right)$. However, the relationship of depth and $g_{\mathrm{S}}$ in well-watered plants may not be meaningful as a result of low $R^{2}$. However, in the no-water plots, the analysis indicated that the deepest depths $(80$ to $100 \mathrm{~cm})$ are most important for TF regarding variation in $g_{\mathrm{S}}(F<0.0001$ and $\left.R^{2}=0.993\right)$, whereas the $40-$ to $60-\mathrm{cm}$ depth for $\operatorname{KBG}\left(F=0.0003\right.$ and $\left.R^{2}=0.991\right)$ are most important (Table 1). The stepwise regression supported evidence in Figures 5 and 6 indicating that TF extracted more water from the deeper soil and became water stressed when that layer was depleted, whereas KBG $g_{\mathrm{S}}$ was more sensitive to soil water depletion in the top soil layer.

\section{Discussion}

Turfgrass has limited stomatal control over transpiration as a result of low height and a thick boundary layer where the leaf surface is completely decoupled from conditions in the air outside the boundary layer (Javis and McNaughton, 1986). Thus, the evapotranspiration continued even when stomata closed (Harris and Tullberg, 1980), during which water is plausibly lost through the cuticle (Cowan, 1977) resulting in rapid water depletion in soil.

As the soil dried, both $\mathrm{TF}$ and $\mathrm{KBG}$ initially approached drought stress at the same rate, indicated from $g_{\mathrm{S}}$ reduction (Figs. 2 and 4). In addition, both species did not moderate internal water potential through stomatal closure, which means the rate of water potential decline in plants was rapid even when stomatal closure occurred immediately after withholding irrigation. Rapid decline in water potential was likely the result of greater boundary layer control over total transpiration from the canopy than stomatal aperture (Zhang et al., 2007).

Both species showed different responses when the soil dried and conditions became severe. KBG stomata seemed to be very sensitive to soil drying, because they closed more rapidly and absolute leaf water potential fell more rapidly than TF. KBG rapidly went dormant with all aboveground tissues 


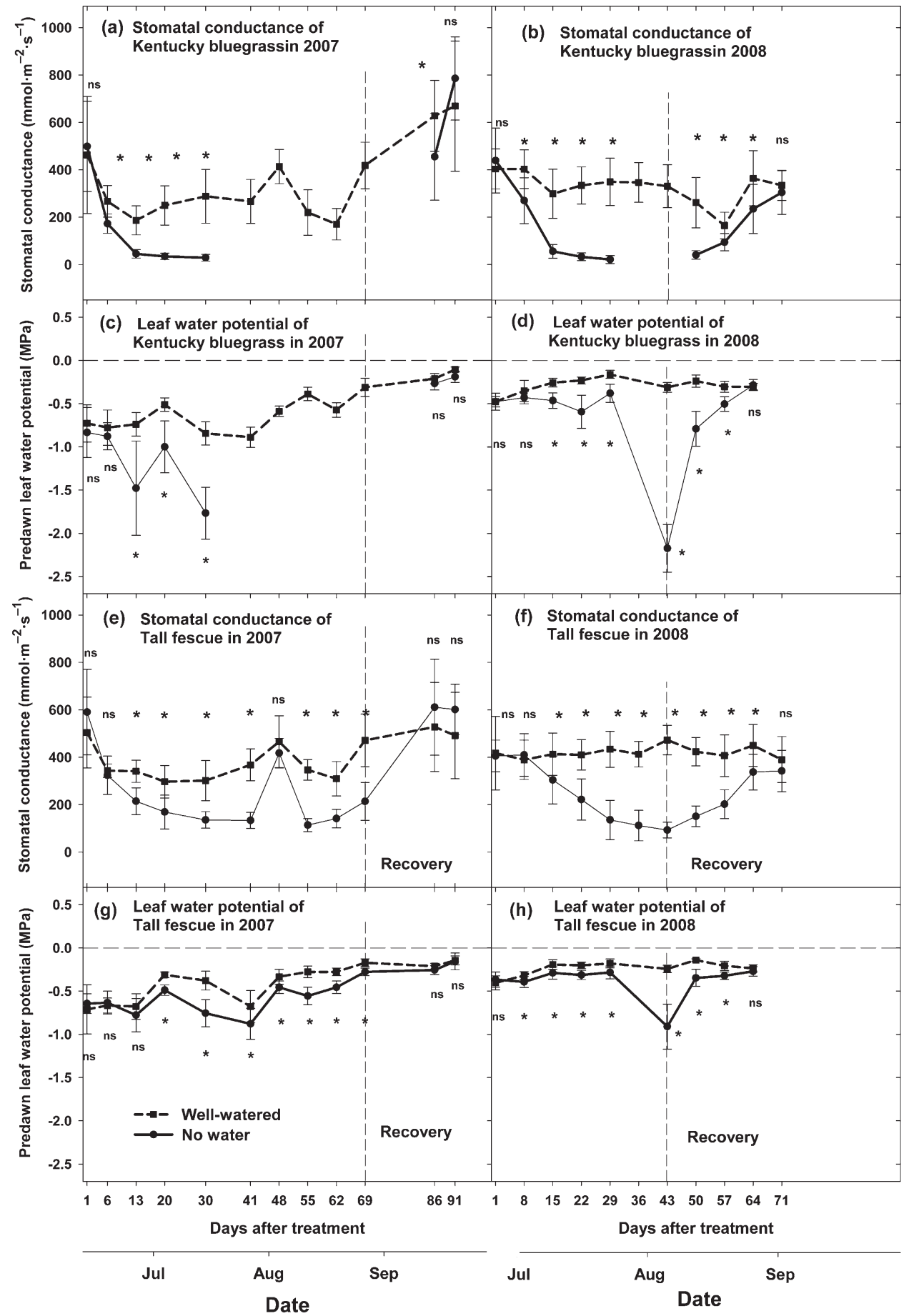

Fig. 2. Stomatal conductance $\left(g_{\mathrm{S}}\right)$ and predawn leaf water potential in well-watered and no-water plots of 'Midnight' kentucky bluegrass (KBG) in (A, C) 2007 and (B, D) 2008 and of 'Gazelle' tall fescue (TF) in (E, G) 2007and (F, H) 2008. Well-watered plots are represented by a short dash line and no-water plots a solid line. The vertical line indicates irrigation resumption on the no-water plots. Ns represents non-significantly different $(P<0.05)$, whereas the asterisk represents significantly different $(P<0.05)$ between pairs of well-watered and no-water values at each day.

turning brown as a result from increasing $\mathrm{T}_{\text {leaf }}-\mathrm{T}_{\text {air }}$ (Fig. 3C) when $g_{\mathrm{S}}$ fell below $50 \%$ of well-watered levels in potentially a feedforward process (Fig. 3B). A small reduction in $g_{\mathrm{S}}$ from soil drying will reduce transpiration cooling, increasing $\mathrm{T}_{\text {leaf }}-\mathrm{T}_{\text {air }}$ and LAVPD, and diminishing the boundary layer through increased eddy turbulence convection. Increased heating and a decreased boundary layer in turn would push conductance even lower and LAVPD higher in a feed-forward loop resulting in more and faster browning of tissues (Figs. 2 and 3). KBG appeared to reduce $\psi_{\text {leaf }}$ more than $\mathrm{TF}$, suggesting that it can extract soil water at lower contents in the top layers to the point of triggering the feedforward stomatal closure cascade. At that point, the plants became dormant — a drought tolerance mechanism to avoid greater physiological damage to meristematic tissue and roots from water stress (Fry and Huang, 2004). As irrigation was resumed, the rapid resump- tion of growth occurred indicating that the rapid KBG dormancy allowed the meristematic growing points to survive under severe stress until the first fall rains coupled with cooler temperatures under natural field conditions (Laude, 1953). The physiological recovery time in no-water plots in our study was $\approx 3$ to 4 weeks after irrigation was resumed. Deeper rooting and maintenance of green foliage showed that $\mathrm{TF}$ did not reach the point over two growing seasons, one 


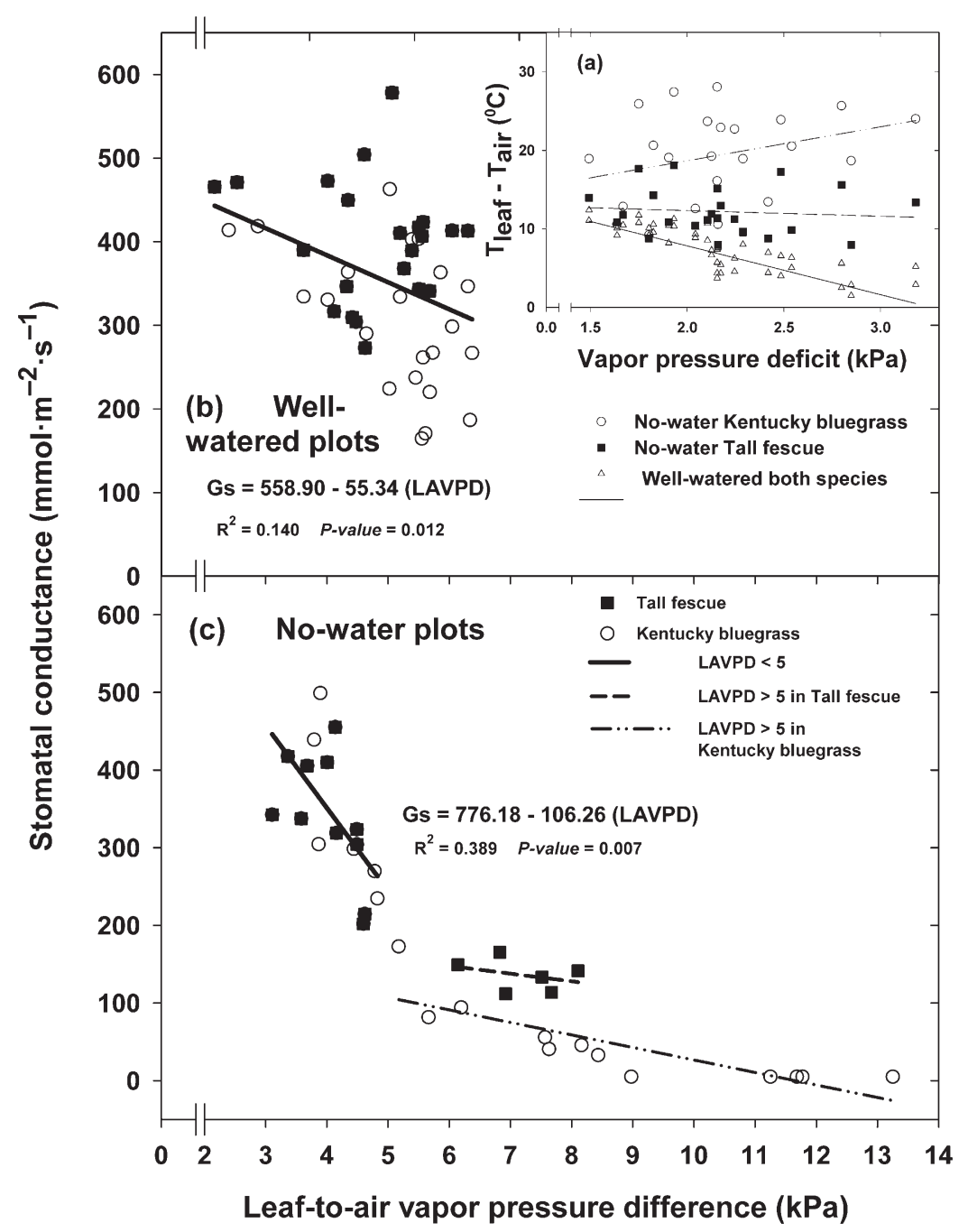

Fig. 3. The difference between air and leaf temperature over the range of VPD in well-watered of both species (solid line), in no-water 'Midnight' kentucky bluegrass (KBG) (dash-dot-dot line), and in nowater 'Gazelle' tall fescue (TF) (short dash line) (A); and the relationship between leaf-to-air vapor pressure difference (LAVPD) and stomatal conductance $\left(g_{\mathrm{S}}\right)$ in $(\mathbf{B})$ well-watered plots and $(\mathbf{C})$ nowater plots with the equation for LAVPD less than $5 \mathrm{kPa}$. The $g_{\mathrm{S}}$ at LAVPD greater than $5 \mathrm{kPa}$ was shown in two lines, in which the short dash line represented 'Gazelle' TF and the dash-dot-dot line represented 'Midnight' KBG. VPD = vapor pressure difference.

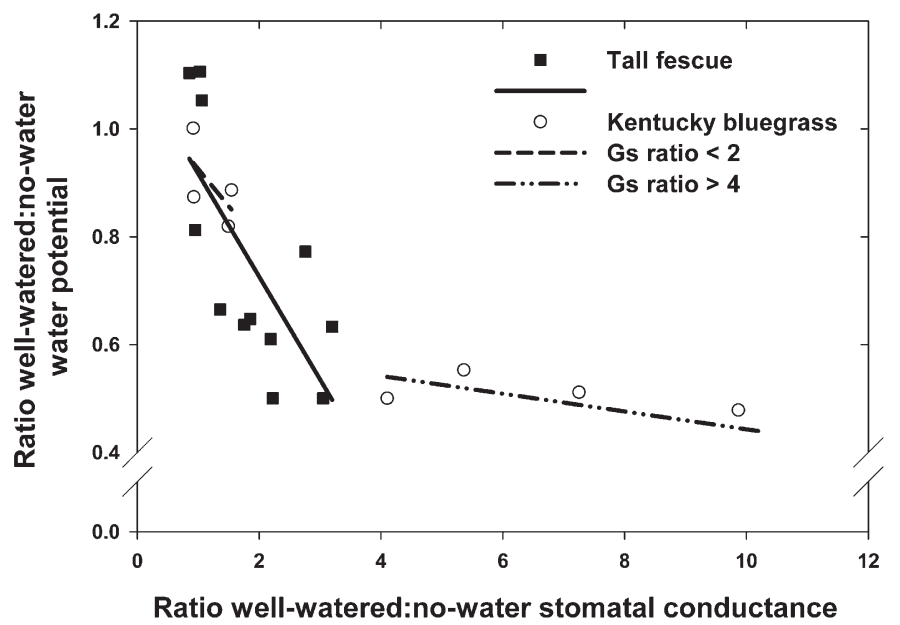

Fig. 4. The ratio of well-watered:no-water leaf water potential to stomatal conductance $\left(g_{\mathrm{S}}\right)$. Kentucky bluegrass lines divided into the $g_{\mathrm{S}}$ ratio lower than 2 (a short dashed line) and the $g_{\mathrm{S}}$ ratio higher than 4 (a dash-dot-dot line) of $g_{\mathrm{S}}$. being exceptionally hot, where meristematic growing points were injured. Thus, when the water resumed, rapid resumption of normal growth occurred almost at the same time as KBG.

TF could be classified as a drought-evader (Fry and Huang, 2004). It kept the aboveground tissues green because the deep root system allowed the plants to extract more water from deeper soil (Figs. 5 and 6). Initially TF responded to soil drying similarly to KBG but reached a steady state between reduced transpiration and higher temperature (convective heat dissipation). Droughtstressed TF thus maintained open stomata at $\approx 30 \%$ of well-watered levels and presumably continued photosynthesis that appeared to be in a steady-state balance with water potential at approximately half of wellwatered levels (Fig. 4) through extracting from increasingly deeper soil depths (Figs. 5 and 6).

In several studies, TF has been shown to have significantly more root mass, as measured by root length, at all depths under drought conditions compared with KBG (Ervin and Koski, 1998; Sheffer et al., 1987) and had three to 12 times greater root length in the lower profile $(60$ to $80 \mathrm{~cm}$ ) in the field condition ( $\mathrm{Su}$ et al., 2008). This larger root system and greater ability to obtain water enable $\mathrm{TF}$ to maintain consistent rates of transpiration resulting in cooler surface temperatures (Fig. 3C) during drought compared with KBG.

Under well-watered conditions, both species showed similar responses to the high desert environments during summer. When water became limited, TF showed the ability to extract water from deeper in the soil profile as water content in the top layer depleted (Table 1; Figs. 5 and 6). This allowed TF to maintain green leaves longer than KBG. TF relies on the deep root system to tolerate drought and may become fatally stressed in typically shallow urban landscape soils because the ability to avoid drought with deep rooting is lost. $\mathrm{KBG}$, in contrast, goes dormant rapidly and preserves the growing point, which makes it more suitable for shallow soil. However, its rapid feed-forward descent into dormancy in response to emergence of localized soil drying from nonuniform irrigation application (Kjelgren et al., 2000) may result in overirrigation to avoid the browning of aboveground tissue.

Under high desert conditions of the IMW, TF has the ability to extract water from deep in the soil profile thereby minimizing irrigation as well as labor and other inputs associated with irrigation. Where water conservation and maintenance of green cover is the highest priority, TF may be better adapted than KBG as long as TF is able to root deeply. As a result, aboveground tissues of TF would stay green as long as there is water in the soil profile. However, TF is likely to perform less well if the soil is shallow and its root system is not able to penetrate deeply, causing soil water depletion to occur more rapidly. Therefore, in this case, KBG would be better suited because 


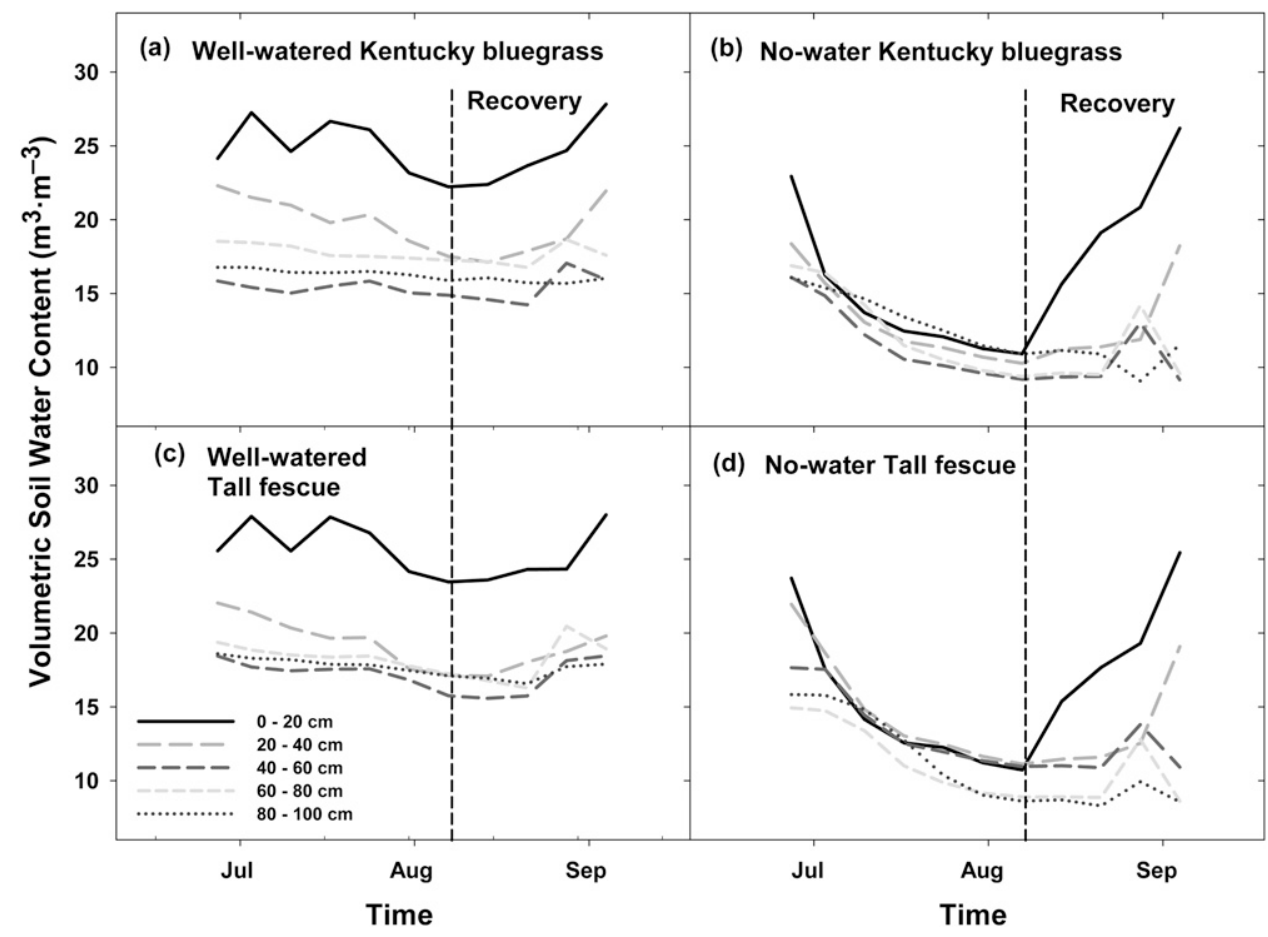

Fig. 5. Volumetric soil water content at each 20-cm depth of well-watered plots of (A) 'Midnight' kentucky bluegrass (KBG), (B) 'Gazelle' tall fescue (TF), and of no-water plots of $(\mathbf{C})$ 'Midnight' KBG, and (D) 'Gazelle' TF. The vertical line indicates irrigation resumption on the no-water plots. In no-water plot, the short dashed line $(40$ to $60 \mathrm{~cm}$ ) depth was the most depleted in volumetric soil water content in KBG (B), whereas the dotted line $(80$ to $100 \mathrm{~cm})$ depth in TF decreased the most from the beginning of the experiment (D).

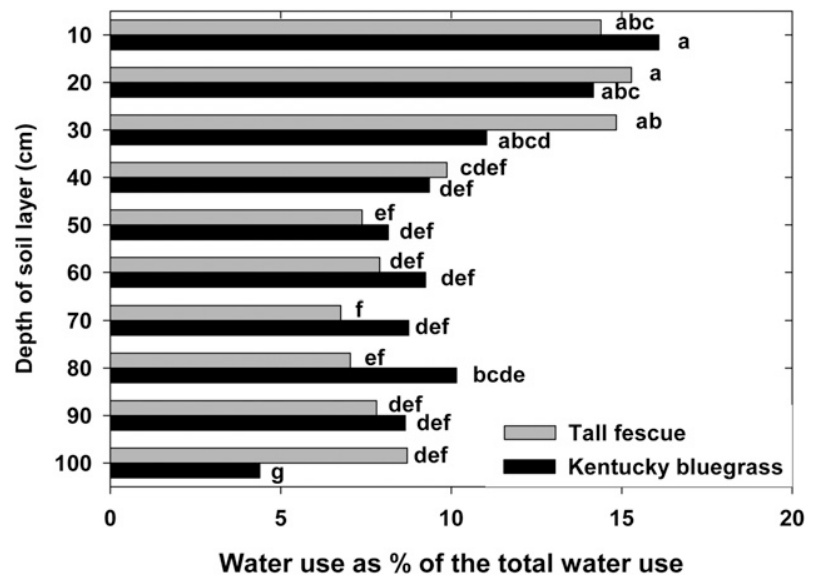

Fig. 6. Percent water use by plants in each $10-\mathrm{cm}$ depth as a percent of the total water use (1-m depth) of 'Midnight' kentucky bluegrass (KBG) and 'Gazelle' tall fescue (TF) in no-water plots was calculated using the difference of soil water content between the start and the end of the experiment days before rewatering and timed by the depth $(10 \mathrm{~cm})$ in each depth over the total from all depths $(100 \mathrm{~cm})$. The same letters are not significantly different $(P<0.05)$ in water use.

Table 1. Correlation efficiency and $P$ value of stomatal conductance $\left(g_{\mathrm{S}}\right)$ with volumetric soil water content at 20 -cm interval depths.

\begin{tabular}{lcrcrr}
\hline & \multicolumn{5}{c}{ Soil depth $(\mathrm{m})$} \\
\cline { 2 - 6 } Species $\times$ treatment & $0-0.2$ & $0.2-0.4$ & $0.4-0.6$ & $0.6-0.8$ & $0.8-1.0$ \\
\hline Well-watered 'Midnight' KBG & $0.367^{z}$ & 0.546 & 0.673 & $\mathbf{0 . 7 1 3}^{\mathbf{x}}$ & 0.570 \\
& $0.267^{y}$ & 0.082 & 0.023 & $\mathbf{0 . 0 1 4}$ & 0.067 \\
Well-watered 'Gazelle' TF & $\mathbf{- 0 . 6 4 2}$ & -0.488 & -0.331 & -0.019 & -0.306 \\
& $\mathbf{0 . 0 3 3}$ & 0.128 & 0.320 & 0.956 & 0.360 \\
No-water 'Midnight' KBG & 0.905 & 0.980 & $\mathbf{0 . 9 9 6}$ & 0.967 & 0.955 \\
& 0.034 & 0.003 & $\mathbf{0 . 0 0 0 3}$ & 0.007 & 0.012 \\
No-water 'Gazelle' TF & 0.821 & 0.885 & 0.942 & 0.982 & $\mathbf{0 . 9 9 7}$ \\
& 0.023 & 0.008 & 0.002 & $<0.0001$ & $<\mathbf{0 . 0 0 0 1}$ \\
\hline
\end{tabular}

${ }^{\mathrm{z} C}$ Correlation coefficient.

${ }^{y} P$ value.

${ }^{\mathrm{x}}$ Bold type indicates the depth with the greatest contribution to changes in $g_{\mathrm{S}}$ using stepwise regression. $\mathrm{KBG}=$ kentucky bluegrass; $\mathrm{TF}=$ tall fescue . it would go dormant rather than suffer damage as TF would be liable to do.

\section{Literature Cited}

Abdu, H., D.A. Robinson, and S.B. Jones. 2007. Comparing bulk soil electrical conductivity determination using the DUALEM-1S and EM38-DD electromagnetic induction instruments. Soil Sci. Soc. Amer. J. 71:189-196.

Al-Faraj, A., G.E. Meyer, and G.L. Horst. 2001. A crop water stress index for tall fescue (Festuca arundinacea Schreb.) irrigation decision-makingA traditional method. Comput. Electron. Agr. 31:107-124.

Aronson, L.J., A.J. Gold, and R.J. Hull. 1987. Coolseason turfgrass responses to drought stress. Crop Sci. 27:1261-1266.

Bates, L.M. and A.E. Hall. 1981. Stomatal closure with soil water depletion not associated with changes in bulk leaf water status. Oecologia 50:62-65.

Blonquist, J.M., Jr., J.M. Norman, and B. Bugbee. 2009. Automated measurement of canopy stomatal conductance based on infrared temperature. Agr. For. Meteorol. 149:2183-2197.

Brown, C.A., D.A. Devitt, and R.L. Morris. 2004. Water use and physiological response of tall fescue turf to water deficit irrigation in an arid environment. HortScience 39:388393.

Carrow, R.N. 1996. Drought resistance aspects of turfgrasses in the southeast: Root Shoot responses. Crop Sci. 36:687-694.

Cowan, I.R. 1977. Stomatal behavior and environment. Adv. Bot. Res. 4:117-228.

Ervin, E.H. and A.J. Koski. 1998. Drought avoidance aspects and crop coefficients of kentucky bluegrass and tall fescue turfs in the semiarid west. Crop Sci. 38:788-795.

Fry, J. and B. Huang. 2004. Applied turfgrass science and physiology. Wiley, Hoboken, NJ. 
Harris, C.E. and J.N. Tullberg. 1980. Pathways of water loss from legumes and grasses cut for conservation. Grass Forage Sci. 35:1-11.

Hetherington, A.M. and F.I. Woodward. 2003. The role of stomata in sensing and driving environmental change. Nature 424:901-908.

Hilaire, R., M.A. Arnold, D.C. Wilkerson, D.A. Devitt, B.H. Hurd, B.J. Lesikar, V.I. Lohr, C.A. Martin, G.V. McDonald, R.L. Morris, D.R. Pittenger, D.A. Shaw, and D.F. Zoldoske. 2008. Efficient water use in residential urban landscapes. HortScience 43:2081-2092.

Huang, B. and H. Gao. 2001. Root physiological characteristics associated with drought resistance in tall fescue cultivars. Crop Sci. 40:196-203.

Idso, S.B. 1982. Non-water stressed baselines: A key to measuring and interpreting plant water stress. Agr. Meteorol. 27:59-70.

Javis, P.G. and K.G. McNaughton. 1986. Stomatal control of transpiration: Scaling up from leaf to region. Adv. Ecol. Res 15:1-49.

Jiang, Y. and B. Huang. 2000. Effects of drought or heat stress alone and in combination on kentucky bluegrass. Crop Sci. 40:1358-1362.

Jiang, Y. and B. Huang. 2001. Osmotic adjustment and root growth associate with drought preconditioning-enhanced heat tolerance in kentucky bluegrass. Crop Sci. 41:1168-1173.

Jones, H.G. 1999. Use of infrared thermometry for estimation of stomatal conductance as a possible aid to irrigation scheduling. Agr. For. Meteorol. 95:139-149.

Kjelgren, R.K., L. Rupp, and D. Kilgren. 2000. Water conservation in urban landscapes. HortScience 35:1037-1040.

Kjelgren, R.K., L. Wang, and D. Joyce. 2009. Water deficit stress responses of three herbaceous native Australian ornamental species. HortScience 44:1358-1365.

Landsberg, J.J. and D.R. Butler. 1980. Stomatal response to humidity: Implications for transpiration. Plant Cell Environ. 3:29-33.

Laude, H.M. 1953. The nature of summer dormancy in perennial grasses. Bot. Gaz. 114:284 292.

Martin, D.L., D.J. Wehner, C.S. Throssell, and T.W. Fermanian. 2005. Evaluation of four crop water stress index models for irrigation scheduling decisions on Penncross creeping bentgrass. Intl. Turfgrass Soc. Res. J. 10:373386.

McCann, S.E. and B. Huang. 2007. Turfgrass drought physiology and irrigation management., p. 432-445. In: Pessarakli, M. (ed.). Handbook of turf grass management and physiology. CRC Press, Boca Raton, FL.

Montague, T., R.K. Kjelgren, and L. Rupp. 2000. Gas exchange and growth of two transplanted, field grown tree species in an arid climate. HortScience 35:763-768.

Monteith, J.L. 1995. A reinterpretation of stomatal responses to humidity. Plant Cell Environ. 18: 357-364.

Murray, F.W. 1967. On the computation of saturation vapor pressure. J. Appl. Meteorol. 6:203204.

Perdomo, P., J.A. Murphy, and G.A. Berkowitz. 1996. Physiological changes associated with performance of kentucky bluegrass cultivars during summer stress. HortScience 31:11821186.

Qian, Y. and J.D. Fry. 1997. Water relations and drought tolerance of four turf grasses. J. Amer. Soc. Hort. Sci. 122:129-133.
Richardson, M.D., D.E. Karcher, K. Hignight, and D. Rush. 2008. Drought tolerance and rooting capacity of kentucky bluegrass cultivars. Crop Sci. 48:2429-2436.

Sheffer, K.M., J.H. Dunn, and D.D. Minner. 1987. Summer drought response and rooting depth of three cool-season turfgrasses. HortScience 22:296-297.

Su, K., D.J. Bremer, S.J. Keeley, and J.D. Fry. 2008. Rooting characteristics and canopy responses to drought of turfgrasses including hybrid bluegrasses. Agron. J. 100:949956.

Turner, N.C. 1991. Measurement and influence of environmental and plant factors on stomatal conductance in the field. Agr. For. Meteorol. 54:137-154.

Turner, N.C., E.D. Schulze, and T. Gollan. 1984. The responses of stomata and leaf gas exchange to vapor pressure deficits and soil water content. I. Species comparisons at high soil water contents. Oecologia 63:338-342.

Volaire, F., G. Seddaiu, L. Ledda, and F. Lelievre. 2009. Water deficit and induction of summer dormancy in perennial Mediterranean grasses. Ann. Bot. (Lond.) 103:1337-1346.

West, C.P., D.M. Oosterhuis, and S.D. Wulischleger. 1990. Osmotic adjustment in tissues of tall fescue in response to water deficit. Environ. Exp. Bot. 30:149-156.

White, R.H., M.C. Engelke, S.J. Morton, and B.A. Ruemmele. 1992. Competitive turgor maintenance in tall fescue. Crop Sci. 32:251-256.

Zhang, Y., T. Kadota, T. Ohata, and D. Oyunbaatar. 2007. Environmental controls on evapotranspiration from sparse grassland in Mongolia. Hydrol. Process. 21:2016-2027. 